\title{
PSYCHOLOGY
}

\section{Peculiarities of development future psychologists' conflict competency}

\author{
I. Biletska ${ }^{1}$ L. Kotlova ${ }^{2 *}$, K. Marchuk ${ }^{3}$ \\ ${ }^{1}$ Department of Foreign Languages Theory and Practice, Pavlo Tychyna Uman State Pedagogical University, Ukraine. \\ ${ }^{2}$ Department of Theoretical and Practical Psychology, Ivan Franko Zhytomyr State University, Ukraine. \\ ${ }^{3}$ Department of Theoretical and Practical Psychology, Ivan Franko Zhytomyr State University, Ukraine. \\ *Corresponding author. E-mail: kotlova.lo@i.ua
}

Paper received 18.10.18; Accepted for publication 24.10.18.

\section{https://doi.org/10.31174/SEND-PP2018-180VI74-18}

\begin{abstract}
In scientific psychological discourse, conflict-related competence is often viewed as a qualitative characteristic and an important component of the individual able to adequately evaluate surrounding reality based on the acquired knowledge. In the context of reforming modern system of education, the main purpose of which is to create conditions for development, self-realization of the individual and ensuring the high quality of education, the problem of conflict competence of students as an ability to resolve and overcome conflict situations in the environment of higher education institutions is actualized. The problem must be solved in connection with the existing contradiction between the objective needs of practical activities and the level of development students' personal characteristics: conflict resistance, empathy, self-confidence, the level of communicative control, etc. The need for studying the peculiarities of students' conflict resistance development is caused by the fact that the influence of various factors on the emergence, occurrence and resolution of conflicts in the educational environment of higher educational institutions remains beyond the attention of researchers. The aim of the study is to diagnose students' conflictual competence. The analysis of structural components reveals the level of formation for determining the appropriate methods of conflict competence development. To achieve these aims, the diagnostic methods were used: the diagnostic test of K. Tomas 'Assessment of the person's tendency to conflict behavior' (an adapted variant of the method by N.Grishina), V. Boyka's diagnostic test 'Diagnostics of the level of empathic abilities' (adapted variant by I. Yusupov), G. Lozhkin's and N. Povyakel's diagnostic test, "Assessment of preparedness for negotiations and conflict resolution", M. Snyder's diagnostic test "Assessment of communicative control in communication". The results of the conducted research reveal the level of development of future psychologists'- university students' conflict competence by motivational, activity, personal, communicative and constructive components. The highest indicators were recorded within the communicative component, and the lowest within the motivational and activity component. The reproductive and intuitive levels of conflict competence development are prevailing for students.
\end{abstract}

Keywords: empathy, competence, communication, conflict competence, conflict, style of behavior.

Introduction. In modern science conflictological competence is interpreted as a complex integral formation, the main components of which are the competence of the subject in his own "I," the competence in the psychological potential of other participants of the conflict; situational competence; knowledge of the conflict; the subject position of the conflict participant.

Psychological knowledge of the rules and non-conflict communication peculiarities and students' behavior in universities helps not only to built constructive interpersonal relationships, but also to apply the ability to reconstruct the conflict, turn it into an instrument of interaction and cooperation during the studying. The knowledge of the factors that cause conflict competence in students environment allows us to develop complex of methods aimed at their prevention and development of skills for successful solutions complex life situations and conflicts.

The analysis of scientific literature (Bashkin, 2009; Zazikin, 1998; Petrovskaya, 1997; Perogonchuk, 2016) suggests that the problem of conflict students' competence caused by discrepancy between the bjective equirements for future professional activity and the not formed number of personal characteristics, such as: the level of communicative control, self-confidence, empathy, etc $[2 ; 13 ; 8 ; 9 ;]$. It should be noted that in the educational environment of the university, the problem of the influence of various factors on the emergence, occurrence and resolution of conflicts, in particular the problem of the formation of student conflict competence, remained beyond the attention of researchers.

The student's period is sensational for the development of the psyche on all levels. They determine man's cognitive development orientation, form a composition of thinking, which characterizes the professional orientation of the individual. For a successful study at the university, a sufficiently high level of general intellectual development is necessary, in particular perception, memory, thinking, attention, and the level of possession of a certain range of logical operations (Ananiev, 1974; Perogonchuk, 2016; Kotlova, 2014) [1; 9; 6]

In the scientific psychological discourse (Petrovskaya, 1997; Fil, 2011), conflict-related competence is often viewed as a qualitative characteristic and an important component of an individual who is capable to assess adequately the surrounding reality on the basis of the acquired knowledge of it In the context of the modern reform in the education system, the main aim of which is to create conditions for development, self-realization of the individual and ensuring high quality of education, the problem of conflict competence of students as an ability to resolve and overcome conflict situations in the university environment is actualized $[8 ; 5]$.

Conflict competence is the cognitive and regulatory subsystem of a professionally significant side of the individual, which contains relevant special knowledge and skills by $\mathrm{V}$. Zazikin (Zazikin, 1998) [13]. It is an element of the individual's social and psychological competence and includes knowledge of the laws of occurrence, development and completion of conflicts, the ability to navigate in a conflict situation, to predict its dynamics, the primary skills of constructive behavior at all stages of the conflict' development, to prevent destructive actions, to complete the conflict with minimal damage for himself and the opponent. 
The studies of the conflict psychology, S. Fil (2011) showed four components structure of conflict-related competence [5]:

- personal (informative, cognitive) - provides for the formation of basic knowledge in the field of conflict science and conflict management, which have practical importance for mastering conflict resolution skills;

- motivational and activity (activity, behavioral) - involves the formation of practical abilities and skills in resolving conflicts (communicative and procedural) on the basis of cooperation;

- communicative - includes the desire and intentions of a specialist to deal with conflicts resolving and organize own further professional development in a specific area of activity, while focusing on the values of conflict-free interpersonal interaction on the basis of cooperation;

- constructive - stipulate the ability of a specialist to reflection and self-reflection, in particular the awareness of his own so-called internal picture of the conflict, which makes it possible to make informed decisions regarding a particular form of behavior in a particular conflict situation.

Purpose and tasks. The purpose of the proposed study is to identify the level of formation future psychologists' conflict competence.

The main tasks of the study:

1. To become acquainted with domestic and foreign experience of studying the problem of the individual's conflictological competence formation.

2. To investigate the structure of students' conflictual competence.

3. To characterize the levels of formation future psychologists'conflict competence.

Conflict competence has a level structure. It is based on a structural and functional feature: competence changes its structure and function in transition to another level (Zazikin, 1998; Wait, 2014) [13; 11].

The indicators of the conflict-related competence formation on the intuitive level are: the search for solutions of conflict situations through systematic trials and errors (students act unconsciously); everyday character of conflictological knowledge and its unsystematic nature; the presence of a conflict is accompanied by uncontrol feelings, unmanageable emotions of irritation, impatience; professionally significant emotions do not dominate; impulsiveness, rigidity, lack of reflection; destructive conflict position.

Indicators of the conflict-related competence formation on the reproductive level are: students' work on the prompt, according to algorithms, superfluity of conflict knowledge, disorder, the presence of mind flexibility, average indicators of components "rigidity", "self-esteem", "impulsiveness", self-doubt, fear, insult, negative attitude toward violence, one-sided assessment of the conflict. The desire to exacerbate the conflict is caused by the motives of a strong disagreement with injustice, misunderstandingю. In the conflict The students with a reproductive level of the conflict-related formation competence often ask for help, advice of a third person disagreement. The conflict is resolved partially.

The indicators of the conflict-related competence formation on the creative and reproductive level are: usage of the formed system of scientific and pedagogical conflictological knowledge, skills, analytical and constructive skills; originality of the decision of pedagogical tasks, the next step of the decision is based on the previous; developed flexibility of thinking; adequacy of self-esteem; formulation of the optimal goal to enter or not to enter in conflict; the desire to see the essence of the conflict; the desire to master the whole system of means and methods of resolving the conflict, the choice of adequate means and methods according to the conflict situation; constructive conflict position.

The indicators of the conflict competence formation on the creative level are: expressed psychological orientation of the individual, sufficient development of analytical, predictive, constructive, performing skills; original ways to solve pedagogical problems; search for new methods, tools, techniques; developed intuition of a higher level; the ability to find a common language not only with individual subjects of vocational and pedagogical interaction (only students or only teachers, administration)in situations of pedagogical conflict, and with all subjects of professional interaction at all levels of the conflict manifestation (internal, personal, interpersonal).

The proposed study is aimed to revealing the levels of formation individual components of conflict competence in students: motivational-activity, personal, communicative, constructive. The study was attended by 100 undergraduate students of II-IV courses.

Research methods. Four groups of diagnostic methods were identified for the determination of the initial level of students' conflict competence formation.

With the help of the first group of techniques, the formation of the motivational and activity component of conflict competence was discovered - diagnostic test of K.Tomas "Assessment of person's tendency to conflict behavior" (adapted version of the method by N.Grishina) (Grishina, 2009) [3].

The object of the diagnosis is the following characteristics of students' practical skills and abilities as: the range of strategies in conflict, the ability to transform conflict interaction into cooperation, the ability to provoke a conflict situation and the ability to maintain conflict interaction.

The second group of diagnostic methods is aimed to the analysis of personal component of conflict competence, which is based on the development of the reflexive sphere, empathy, tolerance, orientation of person in communication diagnostic test of B. Boyko on the level of empathy development (adapted variant of the methodology of I. Yusupov) (Yusupov, 1995) [12].

The third group of diagnostic methods involves identifying a constructive attitude to the conflict - an adapted version of the methodology of G. Lozhkina and N. Povyakel "Assessment of preparedness for negotiations and conflict resolution" (Lozhkin, Povyakel, 2006) [7].

The fourth group of techniques aimed to the diagnosis of communicative skills that manifested in resolving the conflict - adapted version of the test of M. Snyder "Assessment of communicative control in communication" (Reygorodsky, 1998) [10].

Results and discussion. The results of our study confirm the existence of such components in the structure of this students' personal quality, at the same time complementing it with the presence of a communicative and personal component. In particular, empirical data showed the highest indicators for the personal component, and the lowest - for communicative. In addition, the results of the proposed study are consistent with the position of R. Saxton and R. Weight (Saxton, 2012; Wate, 2014), according to which one of the 
causes of conflict behavior is low conflict-related competence $[14 ; 11]$.

Within the framework of the research, the conflict-related competence formation was evaluated according to a number of criteria: psychological and pedagogical awareness of conflicts; constructive attitude to the conflict; developed communicative skills; owning a wide range of conflict behavior strategies; emotional stability; empathy; the ability to "hold" the conflict (not to avoid conflicting interaction); awareness of the importance, significance of conflict-related competence for professional activity.

In the study of the motivational and activity component, it was found that the majority of second- and third-year students tend to compete $(26.5 \%, 42.5 \%)$, which determines their increased aggressiveness and persistence in defending their own point of view during interaction, which in its turn, often leads to conflict. However, the fourth-year students are more likely to cooperate and compromise $(29.7 \%, 27.1 \%)$ during the interaction. The ability to avoid and constructively resolve interpersonal conflicts indicates the motivational and activity component formation on reproductive $(43.5 \%)$ and creatively and reproductive $(24.3 \%)$ levels.

The investigation of the personal component of conflictrelated competence was carried out by diagnosing of students-psychologists' level of empathy as the ability to understand feelings, mental states of another. It was found that only $43.3 \%$ of the respondents have an average level of empathy inherent in the overwhelming majority of people. In interpersonal relations, they are more inclined to make a person's assessment by the actions than on the basis of personal impression. They are characterized by emotionality, mostly controlled. They are attentive, aspire to understand more than it was voiced in communication, but lose patience with excessive expression of feelings of the interlocutor. While reading artistic works and watching films, more often follow the action than the experiences of heroes.

High levels of empathy are typical for $16 \%$ of students. They are sensitive to the needs and problems of surrounded people, generous, inclined to excuse. They are interested in the life stories of others. They are emotionally sensitive, sociable, establish contact quickly. In the assessment of events they trust more their feelings and intuitions than analytical conclusions. They prefer to work with people than alone.

Among the studied $35 \%$ have a low level of empathy. They have difficulties in establishing contacts with people; they feel uncomfortable in a large company. Emotional manifestations in the actions of surrounded people, sometimes seemed to be incomprehensible and devoid of meaning. They prefer individual employment, rather than working with people. They are adherents of precise wording and rational decisions. They appreciate others for business qualities.

Very low level of empathy were found in $5.7 \%$ of students-psychologists. It is difficult for them to be initiative in communication. They usually keep away in a circle of friends, it is especially difficult for them to establish contact with children and persons who are much older. In interpersonal relationships often find themselves in an awkward position, often do not find an understanding with others. In activity they are too centered on themselves and can be very productive in individual work. They are ironic to the sentimental manifestations, painfully react to criticism to their address, although they may not respond to it violently. The revealed level of students-psychologists' empathy testifies the formation of their personal component of conflict-related competence on creatively and reproductive (43.3\%), reproductive (35\%), intuitive (5.7\%) and creative (16\%) levels.

The results of the study of the communicative component of conflict-related competence indicate that there is a certain dynamics in the development of students' communicative control during the studies at the university. Thus, the number of students with a high level of communicative control development in the IV course increases by $35 \%$ compared with the II course, this may be connected with the development of such professional qualities of future psychologists as: entrying in any role easily, flexibility to respond the changes of situations, propensity to predict, ability to keep pace with time, to improve knowledge and skills, ability to manage their emotions.

Characteristic features of the students with an average level of communicative control are: sincerity, spontaneity of behavior; incontinence in emotional manifestations and tendency to affects, insults, conflicts; the tendency to take into account the interests of others, low self-regulation.

The gratest number of respondents of second course (45\%) have a low level of communicative control. This may indicate that they have inherent stability of behavior, they do not consider it necessary to change depending on the situation and do not take into account the communicative and personality features of the interlocutor, as well as the peculiarities of the situation. They are prone to spontaneous and sincere self-disclosure in communication, sufficiently direct and frank. They are "inconvenient" participants of communication due to excessive straightforwardness and inflexibility, the "I" stability, because of low propensity to changes and high - to stereotypes. The obtained results indicate that $18.1 \%$ of students have a creative level of conflict competence formation on a communicative component, on creative and reproductive $-23.7 \%$, reproductive $-28.6 \%$, and intuitive $-29.6 \%$.

In the study of the constructive component, it was found that for students of the second course the prevailing is the lower than the average level of readiness to resolve conflicts $(25 \%)$, which indicates the lack of knowledge, skills and abilities in the solution and prediction of the conflict, the unwillingness to assume responsibility for resolving the conflict. For students of the third course, the level is slightly higher than the average (38\%), and students of the IV course have a high level (40\%) of readiness to resolve conflicts.

The results of the study indicate that students psychologists are generally aquainted with the concept of conflict, understand its nature, know how to solve it. Thus, $37.6 \%$ of students have a level of awareness that is slightly above the average; the average level is found in $20.8 \%$ of students, the level above the average have $16.7 \%$ of students, and the high level is characteristic for $20.8 \%$ of the students. However, as regards the ability to use knowledge and ability to resolve conflicts at the subjective level, only in the IV course students were diagnosed high-level $(37.5 \%)$, while in the studied II and III courses were diagnosed the average level (33.4\%). The level of formation of the constructive component of students' conflict competence is characterized by intuitive (36.6\%) and reproductive (37.5\%) levels of knowledge and skills usage in predicting and resolving the conflict, $13.6 \%$ creative and reproductive, and only $12.3 \%$ - 
creative, due to lack of knowledge about technologies and methods of conflict resolution and inability to use them.
Characteristics of levels of conflict-related competence formation for personal, motivational, activity, communicative and constructive components are presented in the table.

Table 1. Levels of formation Students' Conflict Competence ( in \%)

\begin{tabular}{|l|c|c|c|c|}
\hline \multirow{2}{*}{\multicolumn{1}{|c|}{ Levels }} & \multicolumn{4}{c|}{ Components } \\
\cline { 2 - 5 } & $\begin{array}{c}\text { Motivationaland } \\
\text { activity }\end{array}$ & Personal & Communicative & Constructive \\
\hline Creative & 12,0 & 16,0 & 18,1 & 12,3 \\
\hline Creative and reproductive & 28,0 & 33,3 & 23,7 & 13,6 \\
\hline Reproductive & 43,5 & 35,0 & 28,6 & 37,5 \\
\hline Intuitive & 16,5 & 5,7 & 29,6 & 36,6 \\
\hline
\end{tabular}

Consequently, the highest indicators of the conflictual competence formation in students were obtained by the communicative component $(18.1 \%)$, while the lowest ones were based on motivational and activity (12.0\%) and constructive $(12.3 \%)$. The most pronounced are reproductive $(43.5 \%)$ and intuitive $(29.6 \%)$ levels of students' conflict competence formation. In order to optimize the development of students-psychologists' conflict-related competence at the stage of professional development productive is the use of special development programs, one of which may be social and psychological training.

Conclusions. Within the framework of the proposed work, the level of formation of the conflict-related competence of students-psychologists was revealed.

1. Conflictological competence is considered as a qualitative characteristic and an important component of the personality, which is capable adequately assess the surrounding reality on the basis of acquired knowledge about it. The formation of students conflict competence is studied taking into account the age peculiarities of youth, within the formation of character, assimilation of the basic social roles, the formation of the basic position of life, develop moral and value, aesthetic, emotional and sensory spheres. Students' conflict competence are considered as the ability to resolve and overcome conflicts in the university environment.

2 . The structure of the future psychologist's conflict competence includes motivational and activity, personal, com- municative and constructive components. The highest indicators are recorded within the personal component, and the lowest - communicative. Such results indicate the need for development a communicative component that plays an important role in the professional development of a psychologist. Communicative skills play a key role in understanding and resolving conflict situations, eliminating possible semantic misunderstandings between communicants.

3. Four levels of conflict competence formation are distinguished: intuitive, reproductive, creative and reproductive, creative. The results of the empirical research indicate that students' conflict competence is more actively formed on the reproductive and intuitive levels, whereas the formation of it at the creative and creative and reproductive levels is weakly expressed. The revealed indicators show the need to increase the level of students' conflict competence, the ability to solve conflicts on the basis of cooperation, manage emotions in tension situations. This will contribute not only to the prevention of conflicts and their more successful resolution in case of occurrence, but also is a prerequisite for the creation of safe psychological conditions of studying, a favorable social and psychological climate.

The study does not exhaust the entire depth of the problem. Prospects for further research work we see in the development and testing of social and psychological training of conflict-related competence development.

\section{REFERENCES}

1. Ananev, B. G. (1974). The psychophysiology of studenthood.Modern psychological problems in higher education, 2, 82-89 [in Russian].

2. Bashkin, M. V., \& Skvortsova, Yu. V. (2009). Metacognitive aspects of students' conflict competency. The Bulletin of $P$. $G$. Demidov Yaroslavl State University, 1, 50-54 [in Russian].

3. Hrishina, N. V. (2009). Psychological determinants of conflict. Social and psychological problems of teenagers. Moscow, 117 [in Russian].

4. Dolynska, L. V., \& Matiash-Zaiats, L. P. (2010). Psychology of conflict. Kyiv: Karavela [in Ukrainian].

5. Fil, S. S. (2011). Definition, content and structure of students' conflict competency. Scientific notes of the National University "Kyiv-Mohyla Academy". Pedagogical, psychological sciences and social work, 123, 20-24 [in Ukrainian].

6. Kotlova, L. O. (2014). Developing students' conflict competency as a factor of their personal development. Science and education, 5, 162-168 [in Ukrainian].

7. Lozhkin, H. V., \& Poviakel, N. I. (2006). Psychology of conflict: theory and modern practice. Kyiv: Profesional [in Ukrainian].

8. Petrovskaya, L. A. (1997). The nature of conflict competency. The bulletin of Moscow University. Series 14. Psychology, 42-44 [in Russian].9. Perehonchuk N. V. (2016). Formation of future psychologists' professional competence in modern educational environment. Science and education.11, 49-55 [in Ukrainian].

10. Raigorodskiy, D. Ya. (1998). Practical psychodiagnostics. Methodologies and tests. Samara: BAKHRAKH [in Russian].

11. Wate, R., \& McKinny, N. S. (2014). Enhancing conflict competency. The ABNF journal: official journal of Black Nursing Faculty in Higher Education, 25(4), 123-128 [in English].

12. Yusupov, I. M. (1995). Psychology of empathy. Candidate's diesis. Saint Petersburg: Saint Petersburg State University [in Russian].

13. Zazykin, V. G. (1998). Conflict competency as a factor of civil servants' professionalism. Proceedings of the Scientific Practical Conference on "The Russian state and public service at present stage" (pp. 264-266). Moscow: RAGS [in Russian].

14. Saxton, R. (2012). Communication skills training to address disruptive physician behavior. The AORN journal, 95, 602-611 [in English]. $\quad$ Retrieved from https://www.ncbi.nlm.nih.gov/pubmed

15. Jain, S. R., \& Polman, W. A. (2003). Handbook for Trainers on Participatory Local Development AO Regional Office for Asia and the Pacific Bangkok. Thailand [in English]. 